\title{
Prevalence and risk factors associated with HIV/Hepatitis B co-infection among HIV positive patients attending a large hospital in Northern Uganda
}

\begin{abstract}
Annacarla Chiesa ${ }^{1,2}$, Emmanuel Ochola ${ }^{3,4}$, Letizia Oreni ${ }^{1,2}$, Paolo Vassallini ${ }^{1,2}$, Giuliano Rizzardini ${ }^{1}$, Massimo Galli ${ }^{1,2}$

${ }^{1}$ Infectious Disease Unit, Luigi Sacco hospital, ${ }^{2}$ Department of Biomedical and Clinical Sciences, University of Milan, Italy, ${ }^{3}$ St. Mary's Hospital Lacor, Gulu, Uganda, ${ }^{4}$ Gulu University Faculty of Medicine, Gulu, Uganda
\end{abstract}

\section{Background: The available data concerning hepatitis B virus (HBV)} infection in Uganda are limited, particularly in the case of people living with HIV/AIDS (PLWHA), who do not generally undergo routine hepatitis testing when starting antiretroviral therapy (ART). We aimed to determine the prevalence and correlates of the risk of HBV infection, and the effect of co-infection on the outcomes of ART among HIV clients in a busy HIV clinic in a referral hospital in Northern Uganda

Patients and methods: A random group of 1000 PLWHA attending the outpatients' clinic of St. Mary's Hospital, Gulu, Uganda were systematically selected to undergo a rapid hepatitis $B$ surface antigen $(\mathrm{HbsAg})$ after administering a questionnaire. HIV care parameters were obtained from client files. Multivariate logistic regression and general linear model were used for the analysis

\begin{tabular}{|c|c|c|c|c|c|c|c|c|}
\hline Univariate & OR & $\begin{array}{l}\text { OR lower } \\
\text { limit (95\%) }\end{array}$ & $\begin{array}{l}\text { OR upper } \\
\text { limit (95\%) }\end{array}$ & p-value & $\begin{array}{c}\text { Multivariate } \\
\text { OR } \\
\end{array}$ & $\begin{array}{l}\text { OR lower } \\
\text { limit (95\%) }\end{array}$ & $\begin{array}{c}\text { OR upper } \\
\text { limit }(95 \%)\end{array}$ & $\mathrm{p}$-value \\
\hline \multicolumn{9}{|l|}{ Gender } \\
\hline Female & 1 & & & & 1 & & & \\
\hline Male & 1,815 & 1,094 & 3,011 & 0,021 & 1,574 & 0,867 & 2,857 & 0,136 \\
\hline \multicolumn{9}{|c|}{ Refugee camp } \\
\hline no & 1 & & & & 1 & & & \\
\hline yes & 1,657 & 1,022 & 2,686 & 0,041 & 1,760 & 1,039 & 2,982 & 0,036 \\
\hline \multicolumn{9}{|c|}{ HBV in the compound } \\
\hline no & 1 & & & & 1 & & & \\
\hline yes & 3,696 & 1,831 & 7,463 & $<0,001$ & 3,309 & 1,495 & 7,324 & 0,003 \\
\hline Don't know & 1,013 & 0,547 & 1,876 & 0,967 & 0,786 & 0,399 & 1,548 & 0,486 \\
\hline \multicolumn{9}{|c|}{ Current ALT (x 1 U/L) } \\
\hline & 1,006 & 0,997 & 1,015 & $0,221 \|$ & 1,003 & 0,993 & 1,012 & 0,609 \\
\hline \multicolumn{9}{|c|}{$\Delta C D 4\left(\times 100\right.$ cells $\left./ \mathrm{mm}^{3}\right)$} \\
\hline & 0,910 & 0,840 & 0,986 & 0,022 & 0,884 & 0,791 & 0,988 & 0,030 \\
\hline \multicolumn{9}{|c|}{ Months of therapy (x 1 month) } \\
\hline & 0,995 & 0,989 & 1,002 & 0,140 & 0,997 & 0,990 & 1,004 & 0,411 \\
\hline
\end{tabular}

Results: 950 of the 985 evaluable patients (77\% females; mean age 42.8 years) were receiving ART. The overall prevalence of HBsAg was $7.9 \%$ (95\% confidence interval [CI] 6.2-9.6\%), and was significantly lower among the females $(6.8 \%$ vs $11.7 \%$; $\mathrm{p}=0.020$ ). The factors independently related to HBV infection were having lived in an internally displaced persons' camp (adjusted odds ratio [AOR] 1.76, 95\% Cl 1.03-2.98; $p=0.036$ ) and having shored housing with $\mathrm{HBV}$-infected people during childhood (AOR 3.30, 95\% Cl 1.49-7.32; $\mathrm{p}=0.003)$. CD4+ cell counts were significantly lower in the $\mathrm{HBV}+$ patients $(p=0.025)$, and a better CD4+ cell response to $A R T$ inversely correlated with co-infection (AOR 0.88; 95\% Cl 0.79-0.98; $\mathrm{p}=0.030$ )

Conclusions: The observed prevalence of HBV among the PLWHA, though high, may be underestimated. Having family contact and living in refugee camps may suggest person to person HBV transmission which could necessitate the extension of HBV vaccination to PLWHA. A lower prevalence among HIV clients compared to the regional high values (above 17 percent) could indicate the importance of antiviral therapy in possible HBsAg seroreversion, to be explored in future studies
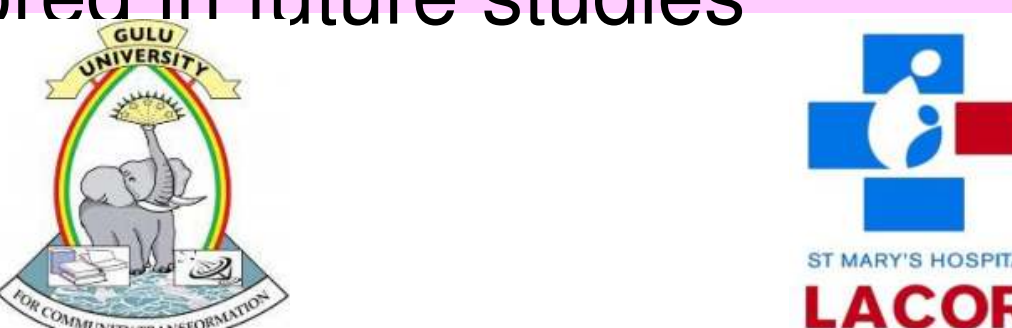